the Society, complete the record of my experience in hepatic surgery up to the end of Jannary, 1891, and I trust they may be of value to the future of this very interesting branch of abdominal surgery.

\section{CHOLERA AMONG THE ASSAM TEA COOLIES.}

By SURGEON-GENERAL A. C. C. De RENZY, C.B.

IN the Sanitary Report of the province of Assam for 1878 I brought to notice some remarkable facts about cholera among the coolies who go up the Brahmaputra river by steamer to work on the tea gardens of Assam. For many years these coolies had suffered frightfully on the passage up the river. A voyage unattended with cholera was the exception rather than the rule, and it was a frequent occurrence for from 10 to 20 per cent. of a batch of coolies to die on the short trip of about fifteen days. In the years from 1871 to 1878 the death-rate on the passage calculated as for a year was 47.8 per cent. of average strength. This terrible mortality had continued for so many years, in spite of all the efforts of the Government to prevent it, that it came to be regarded as unavoidable, and to be due to some mysterious influence which was beyond human power to con. trol. The most perfect cleanliness was maintained on board the steamer; the coolies had ample room on decks, covered by an awning, and open on all sides to the fresh air. They were well fed and well provided with clothing. When I came, as part of my official duty, to investigate this case, I was at first greatly puzzled. My previous experience had lain almost wholly in the Punjab-a province whose climate and sanitary conditions differ entirely from those of Assam. The former has one of the driest climates in the world, the latter one of the moistest; and the difference was equally great in other respects. My Punjab experience had led me to the conclusion that cholera is almost always spread through the medium of water; and that in places where the water-supply was secure against the possibility of excremental pollution, there was very little fear of an epidemic of cholera, even though detached cases of the disease might be brought in from time to time; but that no matter how perfect the sanitary arrangements might be in other respects, if the water-supply was exposed to contamination, most serious epidemics were to be apprehended. I was told that this rule would not hold good in the case of the coolie epidemics, that the coolies were supplied with perfectly pure waterthe same, in fact, as was used by the European passengers and the native crews of the steamers, both of which classes had, for upwards of twenty years, enjoyed almost complete immunity from cholera. Everyone on board used water drawn from the river. I was shown the large iron tanks into which the water was pumped for the use of the coolies, the suspended matter being precipitated by the use of alum. I could not remain insensible to the force of this evidence. I began to think that, after all, there must be something in the explanation of the epidemic among the coolies, which was universally accepted, or the river. It was well known, it was said, that non-Aryan races were specially prone to suffer from cholera, and the great majority of the coolies were non-Aryans. At the same time I could not but recall the many occasions on which I had seen my own Aryan fellow-countrymen, British soldiers, decimated in a few weeks by cholera in the Punjab, and it seemed strange that on the Brahmaputra, over a period of many years, other countrymen of mine, if it were a mere matter of personal susceptibility, should have shown themselves to be so little liable to suffer from the disease while travelling on the same boats, on the same decks, with the sorely alflicted coolies.

A more rational explanation, and one more in accord with experience in all parts of the world, shortly afterwards appeared. During one of my tours of inspection I happened to be on board a steamer with a batch of coolies, among whom cholera was raging, the crew and my fellow-passengers being as usual quite unaffected, and as I lay awake one night in my berth, thinking what could possibly be the cause of the mysteriouslimitation of the attacks, I made up my mind to get up at daybreak and to go aft next morning among the coolies, note their ways and doings, in the hope that I might thus obtain some light. I took up my position in the stern of the vessel near where the latrine was placed, and soon after- wards the coolies began to come down from the upper deck where they slept. I observed that there was a general movement towards a tub which was placed alongside the latrine and was intended for water for ablution after defecation. The coolies dipped their drinking vessels into the water which they used to wash their mouths and faces. Presently a woman came with an infant on her hip, washed the child's clothes in the tub, other coolies came, filled their vessels with the water in which the clothes had been washed, gargled their throats and washed their faces with it, and so it went on for hours. It was at once evident that the tub was a ready means for circulating the cholera contagium, and I ascertained that the doings I have described were of daily occurrence on every steamer carrying coolies. It was true that a pure water-supply was provided for their use; but as there was only one tap in the tank which was to supply four or five hundred coolies, a person would often have to wait a considerable time before he could get supplied, and so the poor ignorant people, to avoid the delay, did not hesitate to use the foul water in the tub. Arrangements were at once made to supply abundance of pure water for ablution, as well as for drinking purposes, under conditions which made it impossible for one coolie to use water which had been in contact with another, with the effect that the epidemics which had lasted so many years suddenly ceased. Isolated cases occurred in coolies who formed part of batches which were known to be infected on their arrival at the port of embarkation; but the mortality at once fell to one-third of the previous average, and remained at a very low figure for ten years, notwithstanding that in that interval the districts from which the coolies are recruited, and the province of Bengal generally, had been visited with several severe epidemics.

Unhappily in 1888 and 1889 there was a return of the old state of things, and the mortality was truly lamentable. In 1888 there were 925 deaths among 31,217 coolies, and in 1889 there were 596 deaths anong 34,507 coolies. In the two years 252 deaths occurred en route to Dhubri, the port of embarkation-and 39L at Dhubri itself; 282 died on board the steamers, and 596 at the depots up the river, at which the atflicted people were landed from the steamers. Nearly all these deaths were due to cholera. It has been said that the renewal of the epidemics shows that the cessation of them was not due to the change in the system of water-supply above described. I think I can show that there is no ground for this contention. Before I left Assam I warned the Government that in order to keep the epidemics in subjection two things were necessary-(1) to provide good water at the halting places en route to Dhubri. So far as the official reports show this has never been done, and on leaving the railway station, forty miles from Dhubri, the coolies have to travel on foot along a road on which the water is no better than ditch water. Under such circumstances it is no wonder that the mortality from cholera en route to Dhubri was so great. The second measure I insisted on was that the water-supply at Dhubri itself should be put into a satisfactory state. When I left it was in a very dangerous state. There was a very badly constructed well, the ground round which was thoroughly polluted by the ablutions of the coolies, and though the coolies were forbidden to take water from the stagnant ponds close by, no amount of vigilance could prevent them from doing so. The water-supply, I believe, remains as it was, and I have no doubt it was an important factor in propagating the contagium brought in by the coolies. The coolies on their arrival at Dhubri are inspected by a medical officer, and every endeavour is made to keep back all who show any signs of illness from going on board the steamers; but it is obvious that in the case of cholera it is only when the symptoms have become some. what pronounced that it can be recognised, and if large batches of coolies go on board in the incubation stage, no matter how perfect the sanitary arrangements may be, the disease will show itself in due time.

Some high Indian anthorities believe that these great epidemics on the Brahmaputra are due to some widespread atmospheric influence which hangs over the great river, and they seem to despair of being able to bring them under control. I do not share this desponding belief, and I feel encouraged to take a more cheery view by the results of the emigration from Goalundo, a port lower down the river than Dhubri. The coolies embarking at Goalundo have to pass Dhubri, and if the calamities which befell the Dhubri coolies were due to atmospheric influence, we should expect 
to find the Goalundo coolies suffering likewise. On the contrary, we find that they passed up with comparatively little loss. In 1888 there were 11 deaths, of which 7 were infants, among 2551 coolies, and in 1889 there were 3 deaths among 1763 coolies. The Goalundo and the Dhubri coolies were in all respects similarly circumstanced, except that the former had not been exposed to the unhealthy conditions existing in the camps en route to Dhubri and at Dhubri itself.

Assam has unrivalled advantages as a field for the employment of the poverty-stricken population of the congested districts of India. But it is idle to expect that the tide of emigration can set in that direction, so long as people have to run the gauntlet of such epidemics as form the subject of this paper, in order to reach the province. My firm belief is that at a very moderate expense the Government might remove the obstacle, with immense benefit to the people of India.

Dublin.

\section{NOTE ON DISTRESSING AWAKENINGS.}

\section{By A. W. MACFARLANE, M.D., F.R.C.P. ED.}

Some persons do not know what it is to rise from sleep in fresh and buoyant spirits; on the contrary, many awake tired and wearied. A few fare even worse, for they awake in the early morning in great distress, and this feeling is replaced, after a time, by weariness and depression. Between the mental conditions of slight malaise and of morning misery all grades of discomfort may be experienced; just as many shades of mental discomfort are associated with the abnormal states that range from slight degrees of neurasthenia up to the more pronounced conditions of hypochondriasis and insanity. Awaking that is not attended by feelings of invigoration and bien-être is abnormal; it betokens some departure from health, or it points to sleeping in unhealthy surroundings. Sleep is a conservative or constructive process. During the activity of daily life the expenditure of nervous energy is rapid, and it preponderates over repair; coincidently, waste products are deposited in the tissues in ratio to the work they effect. The katabolic exceed the anabolic processes, hence the need for sleep. During sleep these conditions are reversed, the expenditure of energy is reduced to a ninimum; the waste products are removed from the economy, and, the reparative processes continuing, potential energy is stored up. When depuration and recuperation are complete, awaking ensues, and the textures being reconstituted and well innervated, the sleeper arises full of power and well-being. A vigorous man awakes full of energy, becange his textures have accomplished these processes. If, however, such a man curtails his sleep unduly, or if by excessive fatigue he charges his tissues with a larger quantity of waste products than he can excrete in the ordinary hours of sleep, his bodily textures are not adequately renovated, and he awakens languid and tired. The feeble and convalescent accomplish such changes slowly and with difficulty; they are often unable to effect the necessary processes in the hours usually allotted to sleep, so they awake from their night's repose tired and jaded. They consequently feel keenly any curtailment of sleep, as well as any unusual fatigue, and this they perceive most on awaking. The personal equation plays an important part in the recuperation of sleep. Such tired awakenings are readily intelligible.

The patients to whom I wish to refer are a class of habitually bad sleepers, who awake every morning more or less wearied and worn out, but who also from time to time, after an unusually deep sleep, awake in great misery. Collectively, they present very similar symptoms, although these may be modified to some extent by temperament and mental development-in short, by the quality of the man. They awake in the early morning, usually from 4 to 5 o'clock, in much distress, covered with cold perspiration, and they lie tortured by evil forebodings for an indefinite time. The mental distress usually begins before sleep terminates; they are conscious that it awakens them, and occasionally they find themselves groaning. They do not recollect that the sensation had its origin in a terrifying dream, nor do they associate the awakening with dreaming. The acute misery is followed by depression and dread. They attribute the awakenings to sleeping " too deeply," and these bear an intimate relation to morbid sleep. Two patients who are so aftlicted state that they occasionally awake not knowing who they are, or where they are, and without knowing that they have slept until they find out how many hours have passed ; the mental unrest follows. They all agree that the seizures, if they may be so called, are more prostrating than lying awake all night. Such awakenings do not recur with regularity, although in one instance they did so every seventh or eighth night for a time. The patients who suffer in this way are invariably neurotic and neuras. thenic; some are hypochondriacal. They present widely different symptoms during the day, but they all exhibit, in greater or less degree, a lack of mental power and endurance, and they are introspective, self-conscious, and desponding. They dread the unknown; frequently they are restless and yawn and sigh $a$ good deal. They may be divided into two groups. The first are those who have been enervated by excesses, commendable or the reverse ; the second by malnutrition, due to an altered blood-supply. One of the chief differences that I have noted between them pertains to their falling asleep. The first group become depressed towards bedtime, and positively dread going to bed. There is nothing of this in the second-indeed, before a "bad" sleep there is of ten a feeling of exaltation (euphoria). From this they are some. times able to predict the occurrence of such sleep. One patient, who can do so with some certainty, is occasionally deceived, for, in spite of feeling well, too well, and comfortably sleepy, when he goes to bed he grows restless in the act of falling asleep, and, beginning to turn, sleep deserts him. There is a very intimate connexion between the causes that give rise to broken sleep and those which induce morbid sleep.

The causes of this morbid sleep are, I believe, twofold : the one depending on some peculiar condition of the nervous system, the other on toxic causes. Morbid sleep occurs in connexion with many neurotic diseases. Amongst others may be mentioned hysteria, epilepsy, migraine, and asthma. It has also been noticed in pregnancy and at the meno. pause. In all these instances it has been observed that such sleep was not followed by any renovation of the bodily powers, consequently it may be concluded that the tissues were unable to effect their depuration or recuperation. In like manner, those who suffer from morning misery, from neurotic causes, awake wretched instead of invigorated, and sometimes they are afflicted with headache and gastric and biliary derangements. In a lady of advanced age, who was for many years under my care, this morbid sleep was followed by an attack of migraine and a wretched awaking alternately.

Morbid sleep occurs in many toxic conditions; it is common when the blood is surcharged with bile, urea, malarial poison, and it has been noticed to precede an attack of acute gout, and to follow poisoning by the products of digestion (ptomaines?). The morning horror of chronic alcoholism and morphinism is widely reco. gnised. In the case of gout such morbid sleep may be preceded by euphoria, just as that symptom occurs in the initial stages of puerperal and other septic fevers, the exaltation being the first symptom of the poisoning. In the second group of cases under discussion euphoria may precede, and misery follow, the morbid sleep.

The causes which combine to make such awakenings miserablearenumerous. Thenervous tension that existsina healthy person during diurnal activity is lessened during sleep. In the weakly and neurasthenic the store of nervous energy is small in quantity and easily dissipated during daily duties; at night its recuperation is slow and difficult, so that the noc. turnal condition is one of exhaustion. In such a "hopeful" disease as pulmonary consumption sinking and distress in the early morning are often complained of. It is about 4 o'clock that the nervous energy is at its lowest, and death frequently takes place about that hour. This lack of vigour is specially felt after morbid sleep.

There are many grades of normal sleep. During sleep the heart beats more slowly and quietly, the brain becomes comparatively anæmic, and vascular tension is diminished. These changes vary with the depth of sleep. Dr. Graves long ago wrote: "It is between three and five in the morn. ing that the inclination to sleep is strongest; it is about this time that sentinels are most apt to slumber at their posts, and consequently attacks upon camps or cities, made with the intention of effecting a surprise, are usually undertaken about this period of the morning." Quite recently 